Check for updates

The BMJ

Cite this as: $B M / 2020 ; 371: m 4120$ http://dx.doi.org/10.1136/bmi.m4120 Published: 26 October 2020

\section{Covid-19: US approves remdesivir despite WHO trial showing lack of efficacy}

\section{Elisabeth Mahase}

The US Food and Drug Administration has approved remdesivir for adults and children (12 years and over, weighing at least $40 \mathrm{~kg}$ ) who need to be admitted to hospital for covid-19 treatment.

This is the first drug for covid-19 that the FDA has approved. The approval came despite the World Health Organization's Solidarity trial reporting that the drug had little to no effect on 28 day mortality and did not delay the need for ventilation or shorten patients' stay in hospital. ${ }^{1}$ The study, which is available as a preprint and has not yet been peer reviewed, included more than 11000 adults in 405 hospitals across 30 countries, of whom 2750 were randomly allocated to receive remdesivir. ${ }^{2}$

Remdesivir was developed by Gilead Sciences with $\$ 70 m$ in US government funding. It reportedly costs about \$2340 ( $€ 1800$; €2000) to \$3120 per patient, although researchers at the University of Liverpool estimated that the cost to manufacture the drug and achieve a profit was $\$ 0.93$ per dose. ${ }^{3}$

The FDA has recommended that patients who do not need invasive mechanical ventilation or extracorporeal membrane oxygenation (ECMO) should receive remdesivir for five days. This includes a single loading dose of $200 \mathrm{mg}$ on day 1 , then a once daily maintenance dose of $100 \mathrm{mg}$ from day 2 . The duration can be extended to day 10 if the patient does not improve. 4

For patients who need invasive mechanical ventilation or ECMO the recommended treatment duration is 10 days. Remdesivir should be administered through intravenous infusion and must be diluted, the FDA said.

Remdesivir was approved for emergency use by the FDA in May for patients admitted to hospital with severe covid-19. The new approval covers most but not all patients previously included in the emergency use authorisation. Because of this, the FDA decided to reissue an emergency use authorisation to allow remdesivir to be used to treat children in hospital weighing $3.5 \mathrm{~kg}$ to $40 \mathrm{~kg}$ and those under 12 years weighing at least $3.5 \mathrm{~kg}$.

\section{Evidence cited by FDA}

The FDA cited three randomised controlled trials to support the approval. The first was the ACTT-1 trial, funded by the National Institute of Allergy and Infectious Diseases, which included 1062 hospital patients from several countries with mild, moderate, or severe covid-19. The results, published in the New England Journal of Medicine, ${ }^{5}$ reported that patients who received remdesivir had a median recovery time of 10 days ( $95 \%$ confidence interval 9 to 11 days), whereas it was 15 days ( 13 to 18 days) in the placebo group. Additionally, the Kaplan-Meier estimates of mortality were $6.7 \%$ with remdesivir and $11.9 \%$ with placebo by day 15 and $11.4 \%$ with remdesivir and $15.2 \%$ with placebo by day 29 .

The second study was a trial of adult hospital patients with moderate covid-19, which compared remdesivir for five days (191 people) and remdesivir for 10 days (193) with another group receiving the standard care (200). ${ }^{6}$ The trial, run by Gilead Sciences, found that symptoms improved significantly more in the five day group when compared with the group receiving standard of care, but not in the 10 day group.

The third trial cited by the FDA was of hospital adults with severe covid-19, also run by Gilead Sciences. ${ }^{7}$ It compared a five day remdesivir course (200 patients) with a 10 day course (197). On day 14 the odds of a patient's covid-19 symptoms improving were similar in both groups, while recovery and mortality rates were the same.

Dyer O. Covid-19: Remdesivir has little or no impact on survival, WHO trial shows. BMJ2020;371:m4057. doi: 10.1136/bmj.m4057 pmid: 33077424

2 Repurposed antiviral drugs for COVID-19 -interim WHO SOLIDARITY trial results https://www.medrxiv.org/con-

tent/10.1101/2020.10.1520209817vi:ikey=481e7d4baad42b29fabc7437bfc7eeeff97467d8keytype2=tf_ipsecsha.

3 Tanne JH. Covid-19: US should end Gilead's monopoly on producing remdesivir, report says. BM/2020;370:m3537. doi: 10.1136/bmj.m3537 pmid: 32913041

4 Veklury prescribing information. https://www.accessdata.fda.gov/drugsatfda_docs/label/2020/2147870rig1s000lbl.pdf.

5 Beigel JH, Tomashek KM, Dodd LE, etalACTT-1 Study Group Members. Remdesivir for the treatment of covid-19 - final report. NEngl J Med 2020 doi: 10.1056/NEJMoa2007764. pmid: 32445440

6 Study to evaluate the safety and antiviral activity of remdesivir (GS-5734 ${ }^{\mathrm{TM}}$ ) in participants with moderate coronavirus disease (covid-19) compared to standard of care treatment. ClinicalTrials.gov. Mar 2020. https://clinicaltrials.gov/ct2/show/NCT04292730.

7 Study to evaluate the safety and antiviral activity of remdesivir (GS-5734 ${ }^{\mathrm{TM}}$ ) in participants with severe coronavirus disease (covid-19). ClinicalTrials.gov. Mar 2020. https://www.clinicaltrials.gov/ct2/show/NCT04292899

This article is made freely available for use in accordance with BMJ's website terms and conditions for the duration of the covid-19 pandemic or until otherwise determined by BMJ. You may use, download and print the article for any lawful, non-commercial purpose (including text and data mining) provided that all copyright notices and trade marks are retained. 